\title{
Does FANCA Assist CENP-E in Architectural Organization of Chromosomes at Spindle Equator?
}

\author{
Amr Ahmed El-Arabey, Salama Abdu Salama, Adel Rashad Abd-Allah \\ Department of Pharmacology and Toxicology, Al-Azhar University Faculty of Pharmacy, Nasr City, Cairo, Egypt
}

To the Editor,

Fanconi anemia is a complex genetic disorder caused due to a mutation in one of at least 21 Fanconi anemia genes and characterized by developmental abnormalities, congenital malformation, genomic instability, and predisposition to cancer. Indeed, patients with mutation in Fanconi anemia genes, including complementation group A (FANCA), are susceptible to cancer, particularly acute myeloid leukemia and squamous cell carcinoma. Furthermore, Fanconi anemia is associated with different diseases, including congenital abnormalities that may affect all organ systems $(1,2)$. Recently, a novel originator for FANCA mutation has been identified in Romani patients living in the Balkan region (2). The Fanconi anemia proteins play key roles in ensuring proficient DNA damage repair, overcoming replication stress, orchestration of DNA replication, and fine-tuning mitotic checkpoints to ensure faultless chromosome segregation during cell replication. Moreover, FANCA has been implicated in the repair of interstrand DNA crosslinks (3). The study by $\mathrm{Du}$ et al. (4) in 2009 demonstrated that FANCA interacts with the C-terminus of the centromere-associated protein E (CENP-E) in vitro and in vivo. This interaction might suggest a critical role in the mitotic checkpoint signaling pathway. Interestingly, CENP-E is involved in the initial alignment of chromosomes at the spindle equator on the metaphase plate, and therefore, it is required for steady spindle microtubule capture at the kinetochores, which is a critical step in proper chromosome congression during prometaphase.
Basically, siRNA-mediated CENP-E silencing results in the failure of chromosome congression to the equator, which is characterized by the clustering of chromosomes near the poles $(5,6)$. Similarly, a recent study demonstrated that FANCA-null cells are associated with defects in chromosome congression. Indeed, FANCA ensures interphase and mitosis over hematopoiesis in vivo (7). Furthermore, another study revealed that impairment of spindle assembly checkpoint in vivo gives rise to lagging chromosomes, which is an obvious mitotic error in the hematopoiesis of $\mathrm{FANCA}^{-/}$patients (8). Here we would like to shed light on the strong positive correlation between CENP-E and FANCA co-expression reported in 26 studies from The Cancer Genome Atlas data of different types of cancers (Table 1). Furthermore, statistical analysis of mutual exclusivity and co-occurrence of CENP-E and FANCA in 9377 tissue samples from the previously mentioned studies (Table 1) using cBioPortal Cancer Genomics analysis (http://www.cbioportal.org) demonstrated a significant positive correlation $(\mathrm{p}<0.001)$ (Table 2$)$. However, the precise regulatory function of FANCA in ensuring chromosome integrity during mitosis in dividing cells has not yet been elucidated. Collectively, from the previous data, it is clear that FANCA binds to CENP-E and assists in chromosome organization at the spindle equator to ensure timely appropriate chromosome separation (3). Moreover, the current data will open potential new avenue toward the identification of the mechanistic role of FANCA as a DNA repair protein in chromosomal alignment during mitosis.

\footnotetext{
Address for Correspondence: Amr Ahmed El-Arabey, Department of Pharmacology and Toxicology, Al-Azhar University Faculty of Pharmacy, Nasr City, Cairo, Egypt e-mail: ph.amrcapa@gmail.com; amrel_arabey@azhar.edu.eg ORCID ID: orcid.org/0000-0003-0420-7191

Received: 5 June $2018 \quad$ Accepted: 22 June 2018 • DOI: 10.4274/balkanmedj.2018.0709

Available at www.balkanmedicaljournal.org
}

Cite this article as:

El-Arabey AA, Salama SA, Abd-Allah AR. Does FANCA assist CENP-E in architectural organization of chromosomes at spindle equator? Balkan Med J 2018;35:410-1

${ }^{\circ}$ Copyright 2018 by Trakya University Faculty of Medicine / The Balkan Medical Journal published by Galenos Publishing House. 
TABLE 1. Positive correlation between C-terminus of the Centromere-associated Protein E and FA genes, including Complementation group A in different types of cancers

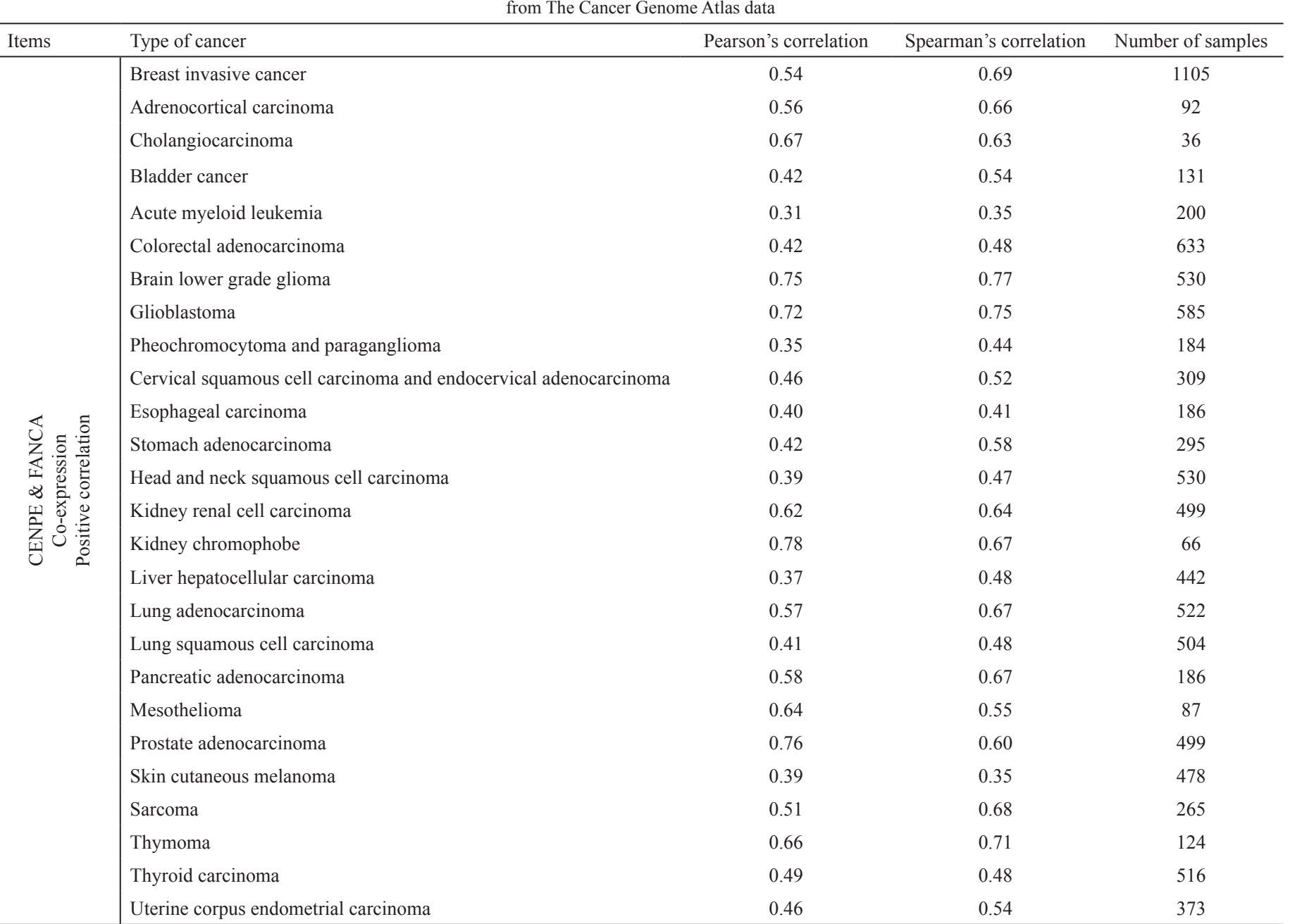

CENPE: Centrosome-associated Protein E; FANCA: Fanconi Anemia genes, including Complementation group A

TABLE 2. Mutual exclusivity and co-occurrence analysis of C-terminus of the centromere-associated protein $\mathrm{E}$ and FA genes, including complementation group A from 26 studies of The Cancer Genome Atlas data (total samples: 9377)

\begin{tabular}{lcccccccrr}
\hline Gene A & Gene B & Neither & Not BA & B Not A & BOTH & Log OR & p value & Tendency & Result \\
\hline CENPE & FANCA & 6412 & 161 & 196 & 22 & 1.497 & $<0.001$ & Co-occurrence & Significant \\
\hline
\end{tabular}

CENPE: Centrosome-associated Protein E; FANCA: Fanconi Anemia genes, including Complementation group A ; OR: odds ratio

Conflict of Interest: No conflict of interest was declared by the authors.

\section{REFERENCES}

1. Giri N, Batista DL, Alter BP, Stratakis CA. Endocrine abnormalities in patients with Fanconi anemia. J Clin Endocrinol Metab 2007;92:2624-31.

2. Dimishkovska M, Kotori VM, Gucev Z, Kocheva S, Polenakovic M, PlaseskaKaranfilska D. Novel Founder Mutation in FANCA Gene (c.3446_3449dupCCCT) Among Romani Patients from the Balkan Region. Balkan Med J 2018;35:108-11.

3. Palovcak A, Liu W, Yuan F, Zhang Y. Maintenance of genome stability by Fanconi anemia proteins. Cell Biosci 2017;7:8.

4. Du J, Chen L, Shen J. Identification of FANCA as a protein interacting with centromere-associated protein E. Acta Biochim Biophys Sin (Shanghai) 2009;41:81621.

5. Cai S, O'Connell CB, Khodjakov A, Walczak CE. Chromosome congression in the absence of kinetochore fibres. Nat Cell Biol 2009;11:832-8.

6. Maiato H, Gomes AM, Sousa F, Barisic M. Mechanisms of Chromosome Congression during Mitosis. Biology (Basel) 2017:6.

7. Abdul-Sater Z, Cerabona D, Potchanant ES, Sun Z, Enzor R, He Y, et al. FANCA safeguards interphase and mitosis during hematopoiesis in vivo. Exp Hematol 2015;43:1031-46.

8. Nalepa G, Enzor R, Sun Z, Marchal C, Park SJ, Yang Y, et al. Fanconi anemia signaling network regulates the spindle assembly checkpoint. J Clin Invest 2013;123:3839-47. 